\title{
Supply Chain Management of Agricultural Technology Innovation: Study of Fujian and Taiwan
}

\author{
Safdar Hussain ${ }^{1} \quad$ Wasim Ahmed $^{1} \quad$ Ambar Rabnawaz $^{2} \quad$ Rana Muhammad Sohail Jafar $^{1} \quad$ Haseeb Akhtar $^{3}$ \\ Yang Jian Zhou ${ }^{1}$ \\ 1.College of Economics, Fujian Agriculture and Forestry University, Fuzhou-350002, China \\ 2.Department of Economics, Faculty of Management \& Administrative Sciences, University of Sargodha-40100, \\ Pakistan \\ 3.University Institute of Management Sciences, PMAS- Arid Agriculture University Rawalpindi, 46000, \\ Pakistan
}

\begin{abstract}
Fujian and Taiwan has shared a strong cross-strait agricultural relation, and the government is keen to further strengthen the trade between the two. There has been substantial growth in the Fujian trade with Taiwan in agricultural goods that has increased more than $\$ 2.7$ billion in 2013 for a year-on-year growth of $70 \%$. This study adopted secondary data collection method to obtain information for the research. The research was mainly qualitative to acquire in-depth information on the matter under study. The findings showed that with the help of e-commerce both Fujian and Taiwan have been benefited with low transaction costs and efficient supply chain management to ensure effective trade.
\end{abstract}

Keywords: Supply Chain Management, Agriculture, E-Commerce, Trade.

\section{Introduction}

Export of agriculture products in Taiwan is majorly dependent upon the mainland market, due to the increasing development of the cross-strait trade in agriculture products. Agriculture trade between Fujian and Taiwan are growing, with outstanding position, where cross-strait agricultural trade accounted for the proportion of trade of agricultural products, agricultural trade between Fujian and Taiwan accounted for more than $40 \%$ of total agricultural trade mainland to Taiwan over the same period, and there is an increasing trend year by year.

January to November 2014, trade between Fujian and Taiwan was recorded up to 389 million, with growth increase of $75 \%$, ranking first in mainland provinces and cities continue to trade (Meidong and $\mathrm{Li}, 2015$ ), while 27 billion dollar investment was recorded between Shanghai and Taiwan during 2013 (Yang, 2015), so due to closest boarders of Fujian and Taiwan can produce big boast in trade, because government has decreased Corporate Income Tax up to $15 \%$ for qualified enterprises (Lee et al., 2015). To optimize the integration of agricultural production and marketing of agricultural products supply chain, supply chain management and technology innovation, reduce intermediate links agricultural trade, building efficient and orderly modern circulation system of agricultural products between Fujian and operation mechanism is particularly important (Gibson and Edwards, 2004; Gunasekaran et al., 2008).

In recent years, rapid development of e-commerce of agricultural products, agricultural trade between Fujian and Taiwan has brought change and opportunity. The agriculture-related e-commerce technology in agricultural trade between Fujian and Taiwan both reduce transaction costs, but also to create a kind of interactive effects of online trading platform. The presence of too many intermediate links and complex problem for this traditional agricultural trade between Fujian and Taiwan, to achieve agricultural online trading is utmost necessity and importance (Ghosh, 1998). So, how Fujian and Taiwan to optimize agricultural production and marketing supply chain integration, application of e-commerce-related technological transformation of agriculture between Fujian and Taiwan agricultural production and marketing of existing supply chain management technology model, built to standardize and improve the market system, various forms of market players, modern circulation system and network information management system is characterized by modern agricultural technology system of supply chain management has become an important research questions need to be addressed urgently (Tseng et al., 2011).

This paper is able to optimize the integration of the supply chain and marketing of agricultural products in Fujian and Taiwan, Fujian and Taiwan agricultural supply chain management innovation and technology to build a modern agricultural products circulation system between Fujian and Taiwan-based supply chain management (Garbi, 2002). As the main research purposes, through the strait between Fujian and existing agricultural marketing and management techniques to investigate patterns and comparative analysis of the factors affecting the performance of the supply chain management of agricultural products between Fujian and Taiwan. The export of agriculture is increasing time to time, therefore Fujian and Taiwan supply chain management of agricultural technology innovation should be studied to improve supply chain management system, which is the core of the development of agricultural trade between Fujian and Taiwan the depth of the supply chain economics analysis of the implementation of online transactions, the need for major aspects of the 
situation between Fujian and Taiwan agricultural supply chain a lot of in-depth (Inkinen and Kaivo-oja, 2009).

\section{Literature Review}

We tried to touch every corner of information from literature review in a way that covers the supply chain management, involving technology innovation, SCM in Agriculture and then we focused towards the SCM in agriculture specifically in Fujian and Taiwan. Researchers made many attempts to find out the factors business can use to go forward in the environment; like resource-based view (Barney, 1991), dynamic capabilities (Teece et al., 1997), strategic agility (Doz and Kosonen, 2008) and blue ocean Strategy (Weill et al., 2002; Kim and Mauborgne, 2005). This research is conducted to make a review of past literature particularly on Supply Chain management technology innovations in agriculture (White et al., 2005).

\section{Understanding the Role of E-commerce in Agricultural Sector}

A higher level of foreign agricultural information to carry out agricultural e-commerce is relatively early. Foreign scholars to produce e-commerce are also focused on the study of e-business models. Rappa (2001) also suggested e-commerce business model for a definition, he believes that a business can be profitable and continue to develop its business model depends on the suitability of the development of enterprises. He also believes that the business model is the core of enterprise survival and development. He also believes that in the current stage of e-commerce, research on the business model is still relatively scarce (Cherian, 2001).

Afuah and Tucci (2000) stated the emergence of e-commerce to improve the company's profitability, he would e-commerce business model comes down to corporate earnings this stage in the future for a long period of time and be able to profit plan. This business model can be summarized as having a value, size, income sources, integrated operations, driving mechanism operatively connected to each part of the system and durability of a variety of system capacity, the system ensures that the system between the operation. E-commerce model on its most basic sense, is the way to do business, a company's survival mode eleven kinds of businesses can generate revenue model, business mode defines the company's position in the value chain, and how to guide their money (Dubosson-Torbay et al., 2002).

On agricultural e-commerce model, domestic scholars from different aspects give their own views. According to the study of Esch $\mathrm{Jr}$ (2002), the money a martial by comparing the B2B, B2C, C2C online trading pattern three agricultural products, think this is a third-party online trading market model (B2B) and businessoriented users as a kind of comprehensive public platform, it is suitable for trade of agricultural products, in a variety of modes, this model is the most practical.

\section{Government and the Development of E-commerce}

Government in the development of e-commerce should play a guiding role in agricultural products, while creating a good environment for development; strengthen the construction of information infrastructure, improve agricultural information system; guide agricultural enterprises and farmers to local conditions to develop ecommerce activities, choose the appropriate business model. Gibson and Edwards (2004) believed that China's agricultural production is mainly decentralized management, homework based, should be chosen as the main mode of B2B, while the model should be improved to accommodate the development of rural areas. Therefore, from trading partners, trading and principal trading activities starting summed up three kinds of mature agricultural e-commerce model.

\section{Technological Advancement and Agricultural Innovation in Supply Chain Management}

To solve the above problem, a need to train people to compensate the seller of agricultural e-commerce economy information chain, leveraging existing public network resources to build e-commerce platform in rural areas, speed up the construction of agricultural standardization system to improve transaction efficiency, through the establishment of a credit system to improve the integrity of the participants awareness programs to ensure the sustainability of agricultural commerce (Mason-Jones et al., 2000).

Ghosh (1998) conducted the analysis of e-commerce, in which participants were divided into M2M model, strategic alliances mode, Mode and User Mode intermediary. Moreover, Zheng et al. (2009) and Baourakis et al. (2002) analyzed e-commerce application mode, which is divided into catalog mode, agricultural information intermediary mode, a virtual community model of agricultural products, agricultural products, electronics store mode, the electronic procurement of agricultural products e-commerce value chain integration in the form of six kinds of e-commerce model electronic auction mode and application mode in general agricultural commerce (Lu and Ramamurthy, 2011).

Garbi (2002) to produce e-commerce model is divided into G2B and G2C mode, B2B model, B2C mode, B2B + C model and the market model and other third parties. Ghosh (1998) on the basis of analysis of the current situation on the agricultural development of electronic commerce, that the impact of e-commerce development of agricultural constraints are low proportion of farmers access, quality of agricultural products is 
not high, there is no system of policies to promote the circulation of agricultural products, the lack of relationship between the various departments internal integration and lack of social science business reputation (Dubosson-Torbay et al., 2002).

Governmental factors mainly in contradiction with the construction of a standardized system lag between the rapid development of e-commerce needs, and the lack of standardization of certification work was carried out. Enterprise factors mainly include: the lower level of their scale and lack of logistics facilities in two ways. Individual farmers factor include: the peasant economy and ideological constraints of agricultural entrepreneurial thinking restricts the development of small-scale peasant agriculture cooperatives in these two areas (Swafford et al., 2006).

Swafford et al. (2008) examined the current flow of agricultural products in Beijing, application of information technology in general, "online pass information, do business under the net," the primary stage, to carry out the necessary conditions and market mechanisms supporting agricultural e-commerce has not yet formed, agricultural e-commerce has not yet appeared in the true sense (Overby et al., 2006). The main reason for this problem is due to both the meaning behind the transaction information, network infrastructure lag, information collection, dissemination mechanism is not perfect, and updating software and hardware infrastructure development and slow (Lu and Ramamurthy, 2011).

\section{Cross-Straits Trade of Agriculture Sector- Challenges}

Wang and Huang (2005) and Lianguang (2014) analyzed agricultural areas of China circulation mode of operation, and considered to enhance the circulation of agricultural model should focus on promoting agriculture and rural informatization construction. Furthermore, Meng-Die (2014) considered the test in order to produce an online trading platform that can really play a significant role, requires two basic elements for sales of agricultural products to solve some problems, namely infrastructure, and second is the market. On the other hand, Lei (2010) also conducted analysis of China's agricultural e-commerce environment using a SWOT analysis method, put forward the strategic development of electronic commerce in agriculture (Nazir and Pinsonneault, 2012).

Esch Jr (2002) analyzed the problems of China's agricultural e-commerce, proposed to improve infrastructure conditions, develop modern farmers and service personnel, strengthen government guidance, improve the level of logistics and other suggestions. It was considered from the legal system construction, logistics and information technology to enhance the agricultural aspects of e-commerce logistics to solve agricultural problems in order to promote the development of agricultural commerce (Tallon and Pinsonneault, 2011).

Garbi (2002) in the case of the development of e-commerce to inspect found in Yunnan, Yunnan agricultural e-commerce is still in its infancy, is still relatively little about the whole Yunnan agricultural ecommerce website, not on the number of scale. He pointed out that e-commerce can be a good remedy for weakness in Yunnan province geographically, in order to enable the development of e-commerce must be able to increase the promotion of e-commerce, allowing more people to join the ranks of e-commerce in the past. While also improving the reliability and operation of the Internet running speed, the government should increase investment in rural infrastructure, establish and improve agricultural e-commerce personnel. Improve the logistics system of agricultural and construction in payment and credit system is also an important measure of ecommerce development.

Agricultural products at home and abroad for more than macroscopic description of e-commerce, there are some with local description of an actual case study of a development, but most are still only a description of the phenomenon and make suggestions (Ghosh, 1998). The study also compares the lack of quantitative research to build respect for the conduct of a combination of local e-commerce model is relatively scarce.

This article from the reality of agricultural trade between Fujian and Taiwan, qualitative and quantitative research methods by combining the analysis of the problems of e-commerce between Fujian and Taiwan agricultural products, agricultural products and try to fit the model of e-commerce development between Fujian and build, good make up for the lack of research in this area. Research on agricultural trade online circulation patterns, relatively speaking, is still in its initial stages, as the literature and depth of research were deficient (Swafford et al., 2008).

\section{Methodology}

The purpose of this study was to examine the agriculture sector of Fujian and Taiwan and the need for technological development in its supply chain management to ensure reduction in costs and efficient delivery of products to the market. Attempts are being made to strengthen the relations between Fujian and Taiwan. Fujian saw trade with Taiwan particularly in agricultural goods which increased substantially in 2013 to $\$ 1.2$ billion. They experienced a $12 \%$ growth in the agricultural trade. Thus, the paper was aimed at investigating the technology integration in the trade relation between the two, for further enhancing the cross-straits relations (Ryan and Bernard, 2000). The study mainly depended on collecting data from secondary sources and examined 
the past studies and current data to see the trend in supply chain management efficiency in agricultural trade between Fujian and Taiwan (Swafford et al., 2006).

The researcher is available with two main sources for collecting data for the study. The data can be collected from secondary sources or primary sources or both. Below is the description of the two main source of data collection that helped in obtaining data to meet the research objectives.

\section{Secondary Research}

Secondary research is conducted to collect information that is readily available and has already been published. The sources of secondary research include online libraries, books, journals, news, magazines and so on. However, it is important for the research to ensure that the data collected from secondary sources is reliable and up-to-date. For this study the data was mainly collected from secondary sources to develop an understanding of the cross-straits relations between Taiwan and Fujian and the ways in which both of them have integrated technology through development of projects to prosper their agricultural trade (Vazquez-Bustelo et al., 2007). The data was collected from news and journal articles that were published to provide an insight to the technological advancement in the supply chain management of the agricultural sector. Moreover, it was ensured that the data collected was not obsolete. The data collected from this study also explored that has resulted from the integration of agricultural technology innovation in the supply chain management of Fujian and Taiwan (Swafford et al., 2006).

\section{Primary Research}

While secondary research ought to collect information from sources that are already published, on the contrary primary research intends to obtain first-hand information. Primary research also known as field research collects most up-to-date information through different methods including interviews, observations, surveys and focus groups. However, there is significant cost associated with collecting primary data and it is also time consuming. Therefore, the researcher had used secondary sourcing for exploring the advantages that have resulted from investing in projects that are developed by Fujian and Taiwan to strengthen their agricultural trade with the help of innovative supply chain management.

\section{Data Analysis and Findings}

Supply Chain Management Technology Innovation: Advantages for Fujian and Taiwan Agricultural

There are several advantages that have resulted from the Fujian and Taiwan agricultural relations with the help of technology innovation. These are likely to include cost advantage, time advantage and others. Internal logistics functions have enabled to save transaction costs to a greater extent. Perishable agricultural products, container equipment needed in circulation and cold storage technology to quality and freshness in circulation requires classification, processing, sorting and other operations. Therefore, the internal functions of Fujian and Taiwan agricultural product logistics, can optimize the allocation of resources, thus saving transaction costs (Tseng et al., 2011).

As the transport distance, refrigeration equipment, insurance function limitations, agricultural supply chain management can supply, production, transportation, plus seamless butt off to achieve "time for space" concept, across the Strait of overcoming create competition time advantage (Gunasekaran et al., 2008).

Agricultural production and consumption dispersion determines the dispersion of market information, it is difficult to fully grasp the information (including market demand, competitors, collaborators); agricultural production caused by seasonal fluctuations in prices of agricultural information with the seasons; fresh agricultural products perishable agricultural products across the region limits the immediate adjustment (Garbi, 2002). Fujian and Taiwan to promote agricultural supply chain management companies to do the relevant information sharing reduce duplication of effort and waste of resources, avoid uncertainty risk (Ryan and Bernard, 2000).

\section{Fujian and Taiwan agricultural supply chain integration Transaction costs}

In Fujian and Taiwan agricultural supply chain system, the supply chain can be seen as a kind of market. For example, all farmers from the sale of production for self-supply chain, farmers need to be the same intermediate product market transaction completed; production ends in a broad sense - in the middle end - the retail end of this supply chain model, the supply chain can as a business, many transactions are done through the enterprise (Swafford et al., 2006). When the agricultural supply chain, the chain between Fujian and Taiwan all nodes within the body as a branch or division of enterprises, then produce all transactions are just internal problems, so it is possible to solve or avoid waste of resources generated by external transaction (Esch Jr, 2002). In this sense, the essence of Fujian and Taiwan produce a stable supply chain is present in the transaction cost savings. 


\section{Efficiency}

Efficiency is an important measure of resource allocation, it solves two problems to maximize profits and minimize losses and so on. Fujian and Taiwan agricultural supply chain efficiency levels generally produce attrition rate, agricultural clearance speed, logistics and distribution efficiency, farm freshness, inventory deployment efficiency, profitability and other indicators to characterize (Rappa, 2001). Fujian and Taiwan agricultural supply chain efficiency largely depends on the level of cultivation technology savvy manufacturers degrees, Fujian and customs clearance speed, performance level, logistics and distribution efficiency middlemen, vendors customer service levels, and between the two the level of cooperation (Gunasekaran et al., 2008).

\section{Network Analysis Based on Supply Chain Management of Agricultural Technology Innovation between Fujian and Taiwan}

Fujian Province vigorously support the development of e-commerce in the country in 2000 first proposed the construction of digital Fujian provincial information currently in the overall level of construction in the country in the forefront. In 2001, the province pioneered the development of e-commerce by drawing up Fujian ecommerce Eleventh Five-Year Development Plan, and the introduction of policy measures to accelerate the development of electronic commerce in 2006 (Swafford et al., 2008). In 2007, under the support of the Ministry of Commerce, Ministry of Commerce, Fujian Province, China Electronic Commerce Center jointly built the country's first regional e-commerce platform, Fujian international e-commerce application platform. The platform started relatively early, rapid development, on this basis, to build a government, finance, business interaction channels, key commodity export base, specialized public information platform, Chinese tea are three sub-platform e-commerce platform, e-commerce on a the development of China's foreign trade in Fujian province has played a very important role. As of 2011, members of Fujian international e-commerce application platform development 13,620 cumulative, covering most of the foreign trade enterprises in Fujian (White et al., 2005).

May 2011, in order to strengthen ties and cooperation with relevant departments in Taiwan, the relevant aspects of cross-strait cooperation in the establishment of the Straits and Taiwan's political base level electronic network in Fuzhou, created a precedent for e-commerce. With the rapid development of the construction market and the agricultural trade between Fujian and Taiwan ship docked points and other infrastructure in the coming period, Fujian will be an important transit for Taiwan agricultural products. With the use of cross-strait investment in agricultural logistics center, both for the development of Fujian and Taiwan agricultural ecommerce provides a good opportunity (Sambamurthy et al., 2003).

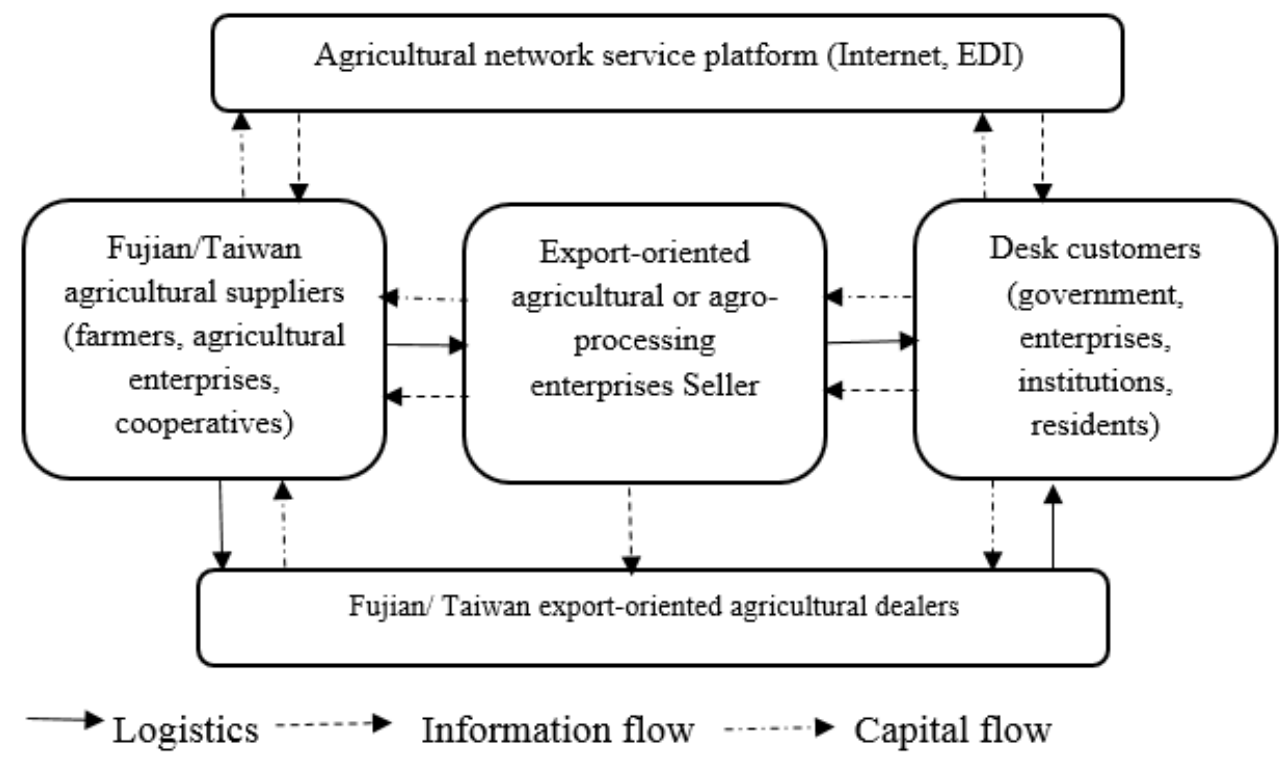

Figure 1. Network Analysis Based on Supply Chain Management of Agricultural Technology Innovation between Fujian and Taiwan

\section{Promoting the Online Circulation System of Healthy Development between Fujian and Taiwan Accelerate agricultural building Web services platform}

Relevant government departments should effectively accelerate agricultural e-commerce platform construction, development and application of network flow network service platform, funds (payment) platform, the sales platform and other services platform. This will enable farmers, agricultural cooperatives and other agricultural 
enterprises, agricultural products or vendors' agricultural products processing enterprises and consumers to conduct real-time online transaction negotiation, understand the relevant information, conduct liquidity, improve the speed of the various participants to reflect information and make decisions in the shortest possible time. Thus, it will ensure seamless agricultural products from farm to fork convergence, improve circulation efficiency of agricultural products, reduce losses and increase farmers' income, but also enables consumers to obtain affordable.

\section{Accelerate the development of agricultural e-commerce}

Produce electricity business is the transformation of the traditional trading patterns, and is a new mode of business activities, but also a new agricultural trading system arrangement. It takes full advantage of the Internet's ease of use, practicality, WAN and interoperability to achieve a rapid and efficient exchange of business information network and business transactions. Therefore, we must strengthen the power of agricultural information platform construction, the implementation of agricultural product quality and safety certification system, strengthen agricultural safety awareness, establish rapid detection and improvement of agricultural systems; strengthen the standardization of agricultural product processing and standardization of bamboo, with preferential policies, administrative measures and market-based instruments support, guide and standardize the implementation of agricultural leading enterprises of agricultural quality standards established by national or international, to achieve a comprehensive standardized quality of agricultural products; fully mobilize all social forces, integration of social resources, the initiative to guide them to actively participate in the construction of agricultural e-commerce, application and promotion .

\section{Establish a sound environment for the development of e-commerce integrity}

Fujian and Taiwan agricultural e-commerce development is inseparable from a sound social credit environment. A good social environment of e-commerce should be encouraged by ensuring honesty and trustworthiness incentives, while the necessary punishment for dishonesty. Let all sectors of society to join in the development of e-commerce to self-regulate, so that each body involved in e-commerce can be self-discipline. Credit may be appropriate to introduce third-party service providers to participate in each of the main agricultural products ecommerce-based independent, impartial, objective and under the principle of credit evaluation. Increase the intensity of an exchange of e-commerce credit information and other credit information, establish a sound social credit system, while the creditworthiness of all e-commerce businesses to classify other supervision and management, so that they can do good faith compliance.

\section{Increase cross-strait communication, eliminate cultural differences}

As the exchange between Fujian and Taiwan, there are still obstacles to the user's Internet connection with a different cultural background. Fujian and Taiwan produce multi-cultural characteristics of e-commerce which cannot be ignored. Because, on the basis of social norms, local standards, religion and language, the cultural property determines how the interaction is between each other. Therefore, it should be to increase communication between the two sides, mutual understanding and recognition of cultural differences, in order to overcome cultural differences. Respect each other's values, eliminating cultural differences on both sides to ensure the smooth development of Fujian and agricultural commerce.

\section{Strengthen e-commerce laws, regulations and construction standards}

It is essential to implement existing laws and regulations, based on the relevant laws and regulations continue to drive e-commerce building, research to determine the whole idea of e-commerce legislation, the adjustment range and specification way to strengthen the legal interpretation, enhancing existing laws and regulations in the field of e-commerce and operational suitability. Focus on improving the normative e-commerce services, ecommerce services to promote the effective implementation of corporate legal obligations and responsibilities, improve the trade body of Identification mechanism to improve information dissemination of e-commerce, credit services, online transactions, electronic payment, logistics, service, dispute processing specification level of service.

\section{Accelerate agricultural e-commerce personnel training}

Pay attention to the cultivation of agricultural e-commerce talent, only a high-quality agricultural products ecommerce personnel in order to better serve the agricultural e-commerce conducted between Fujian and Taiwan. First, help the existing agricultural e-commerce professionals to increase their level of training to have a good grasp of emerging network technologies, e-commerce theory and knowledge management and other aspects of agricultural production, the ability to update their theoretical structure in real time, in practice, agricultural ecommerce in Fujian and Taiwan will not be eliminated by the era. Secondly, for those who can develop agricultural e-commerce college talent, should guide their professional disciplines intensify personnel training 
and e-commerce, e-business to meet the demand for high-quality talent on the agricultural community. Third, encourage training institutions and vocational education training those targeted for business and computer network technology are proficient in complex talent, into the development of e-commerce in agricultural products between Fujian and Taiwan to become the main force in the agricultural e-commerce development between Fujian and Taiwan (Dubosson-Torbay et al., 2002).

\section{Strengthen agricultural supply chain management}

From the overall interests of the supply chain of agricultural departure, strengthen agricultural supply chain management, so that all players in the supply chain to improve operational efficiency, reduce costs and gain a win-win. This requires the need for an integrated agricultural supply chain integration, so that each participant in the network service platform supporting agricultural products, the coordination of all aspects of the operation of various departments. Each participant should make full use of the relevant information and network technology, production and marketing for effective collaboration from many aspects, to ensure marketable agricultural products, the relative balance of supply and demand, in order to avoid false amplification "bullwhip effect" arising from the supply chain needs of farmers, vendors and other damage (Ngai et al., 2011).

In short, the online circulation system of agricultural innovation Fujian and Taiwan or not, will directly affect the cost and efficiency of its circulation, thereby affecting the competitiveness of the agricultural market between Fujian and Taiwan. Thus, by constructing Fujian and Taiwan-based supply chain management of agricultural products and modern circulation system of the network, and to take measures to promote the circulation of agricultural products in order to improve the efficiency of agricultural products circulation between Fujian and Taiwan, increase farmers 'income and improve consumers' interests, promote agricultural development between Fujian and Taiwan and new rural construction in Fujian has important practical significance.

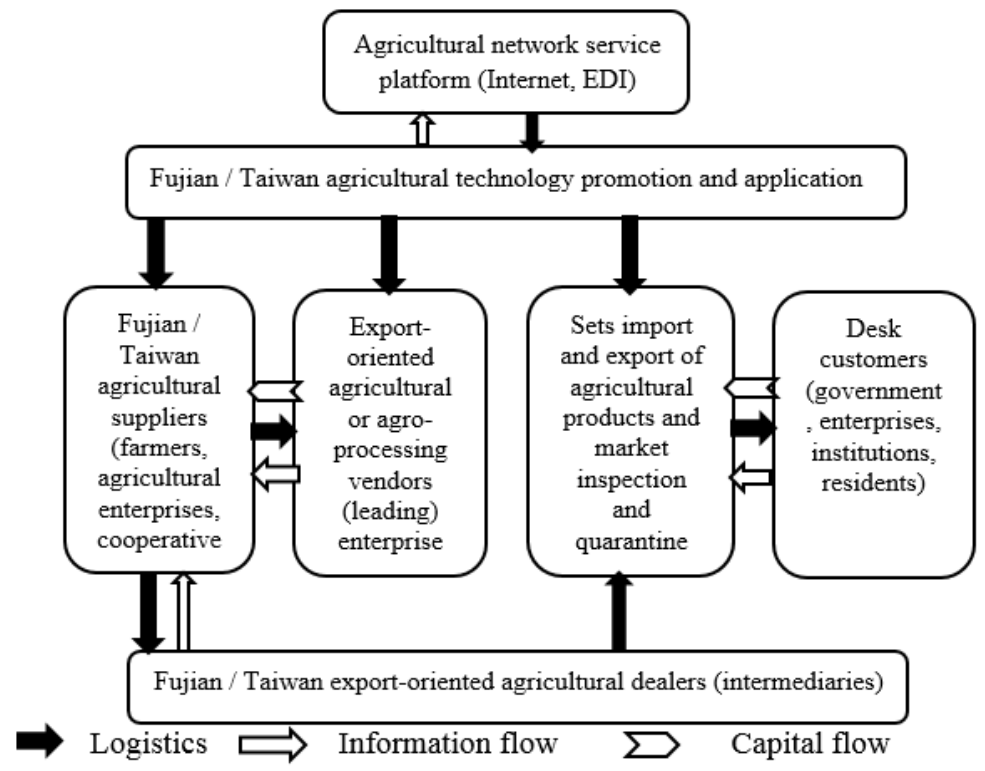

Figure 2. Promoting the Online Circulation System of Healthy Development between Fujian and Taiwan

\section{CONCLUSION}

With a thorough analysis of the data collected from the secondary sources it can be concluded that Fujian and Taiwan share a strong agriculture cross-straits relation. However, the challenges that have resulted from traditional methods of trade are likely to include increased transaction cost and less efficiency can be overcome with the help of adopting technology and innovation. Thus, it is imperative to recognize the importance of ecommerce for facilitating both to have an efficient and cost effective supply chain management. Fujian has approved 48 Taiwan-backed agricultural projects last year that accounted for \$120 million. As a result of these projects 10 countries were singled-out for the demonstration sites for Fujian-Taiwan agricultural cooperation with approximately 100 improved varieties and 130 new techniques from Taiwan. It also facilitated in establishing platforms for agricultural cooperation between the two. Fujian has always been considered as the leader in cross-straits agricultural and other cooperation and was the first to come up with the local regulation promoting cross-straits cooperation in agriculture. The province now has six national Taiwan Farmer Innovation Parks on the mainland out of a total of 29. E-commerce and rapid technological advancement has facilitated in ensuring effective agricultural relation between the two. 
Business competition in the future, e-commerce will play an important role, and some small and medium enterprises and even some farmers aware of it, have put into e-commerce marketing go. However, an SME or a farmer in order to complete the design and implementation of e-commerce system is almost impossible that this investment is also SMEs unbearable. Based on the above analysis, the electronic market to a third party as owners and operators of public electronic market model it has its inherent advantages, can provide a good platform for the trading of agricultural products, such platforms can be compared with the number of buyers and sellers more communication to reach good results under the circumstances inconvenient and more dispersed. Public electronic market model which can be a good addition to reducing transaction costs between buyers and sellers, the ratio in the other two markets.

\section{References}

Afuah, A., Tucci, C.L., 2000. Internet business models and strategies: Text and cases. McGraw-Hill Higher Education. pp. 480.

Baourakis, G., Kourgiantakis, M., Migdalas, A., 2002. The impact of e-commerce on agro-food marketing: The case of agricultural cooperatives, firms and consumers in Crete. British Food Journal 104, 580-590.

Barney, J., 1991. Firm resources and sustained competitive advantage. Journal of management 17, 99-120.

Cherian, E., 2001. Electronic business: the business model makes the difference. Proceedings of the Eighth European Conference on Information Technology Evaluation, D. Remenyi and A. Brown (eds.), MCIL (Reading). Oriel College Oxford, pp.171-174.

Doz, Y., Kosonen, M., 2008. The dynamics of strategic agility: Nokia's rollercoaster experience. California Management Review 50, 95-118.

Dubosson-Torbay, M., Osterwalder, A., Pigneur, Y., 2002. E-business model design, classification, and measurements. Thunderbird International Business Review 44, 5-23.

Esch Jr, A., 2002. Internet II: the adventure continues. Information Management Journal 36, 31-37.

Garbi, E., 2002. Alternative measures of performance for e-companies: a comparison of approaches. Journal of Business Strategies 19, 1-17.

Ghosh, S., 1998. Making business sense of the Internet. Harvard Business Review 76, 126-135.

Gibson, P.R., Edwards, J., 2004. The strategic importance of e-commerce in modern supply chains. Advanced Topics in Electronic Commerce 2, 59-76.

Gunasekaran, A., Lai, K.-H., Cheng, T.C.E., 2008. Responsive supply chain: a competitive strategy in a networked economy. Omega 36, 549-564.

Inkinen, S., Kaivo-oja, J., 2009. Understanding Innovation Dynamics. Aspects of Creative Processes, Foresight Strategies, Innovation Media, and Innovation Ecosystems. FFRC eBook 9/2009. Finland Futures Research Centre, Turku School of Economics, Turku. Finland Futures Research Centre, Turku School of Economics, Turku.

Kim, W.C., Mauborgne, R., 2005. Blue ocean strategy: How to Create Uncontested Market Space and Make the Competition Irrelevant. Harvard Business School Press, pp. 238.

Lee, C., Su, A., Yu, M., Tang, B., 2015. Fujian Pilot Free Trade Zone (1): official launch and release of the overall plan. News Flash, China Tax and Business Advisory, 1-4. www.pwccn.com.

Lei, Z., 2010. Analysis on the Competitiveness of Ningxia Characteristic and Dominant Agricultural Industry Based on SWOT [J]. Journal of Anhui Agricultural Sciences 5, 150.

Lianguang, M., 2014. Study on Supply-Chain of Agricultural Products Based on IOT. Measuring Technology and Mechatronics Automation (ICMTMA), 2014 Sixth International Conference on. IEEE, pp. 627631.

Lu, Y., Ramamurthy, K., 2011. Understanding the link between information technology capability and organizational agility: An empirical examination. Mis Quarterly 35, 931-954.

Mason-Jones, R., Naylor, B., Towill, D.R., 2000. Engineering the leagile supply chain. International Journal of Agile Management Systems 2, 54-61.

Meidong, H., Li, S., 2015. Fujian FTZ to focus on cross-Straits trade with Taiwan. China Daily, http://www.chinadaily.com.cn/business/2015-2003/2013/content_19800236.htm.

Meng-Die, L., 2014. The Development Patterns on the Fresh Agricultural Products in Mobile E-commerce. Logistics Engineering and Management 3, 050.

Nazir, S., Pinsonneault, A., 2012. IT and firm agility: an electronic integration perspective. Journal of the Association for Information Systems 13, 150-171.

Ngai, E.W., Chau, D.C., Chan, T., 2011. Information technology, operational, and management competencies for supply chain agility: Findings from case studies. The Journal of Strategic Information Systems 20, 232-249.

Overby, E., Bharadwaj, A., Sambamurthy, V., 2006. Enterprise agility and the enabling role of information technology. European Journal of Information Systems 15, 120-131. 
Rappa, M., 2001. Managing the digital enterprise-Business models on the Web.

Ryan, G.W., Bernard, H.R., 2000. Data management and analysis methods. In: Handbook of Qualitative Research, 2nd Ed. / Norman Densin and Yvonna Lincoln, Eds. (Thousand Oaks, CA: Sage Publications, 2000), p. 769-802.

Sambamurthy, V., Bharadwaj, A., Grover, V., 2003. Shaping agility through digital options: Reconceptualizing the role of information technology in contemporary firms. MIS Quarterly 27, 237-263.

Swafford, P.M., Ghosh, S., Murthy, N., 2006. The antecedents of supply chain agility of a firm: scale development and model testing. Journal of Operations Management 24, 170-188.

Swafford, P.M., Ghosh, S., Murthy, N., 2008. Achieving supply chain agility through IT integration and flexibility. International Journal of Production Economics 116, 288-297.

Tallon, P.P., Pinsonneault, A., 2011. Competing perspectives on the link between strategic information technology alignment and organizational agility: insights from a mediation model. MIS Quarterly 35, 463-486.

Teece, D.J., Pisano, G., Shuen, A., 1997. Dynamic capabilities and strategic management. Strategic Management Journal 18, 509-533.

Tseng, M.-L., Wu, K.-J., Nguyen, T.T., 2011. Information technology in supply chain management: a case study. Procedia-Social and Behavioral Sciences 25, 257-272.

Vazquez-Bustelo, D., Avella, L., Fernández, E., 2007. Agility drivers, enablers and outcomes: empirical test of an integrated agile manufacturing model. International Journal of Operations \& Production Management 27, 1303-1332.

Wang, N., Huang, L., 2005. A Study on Agricultural Product Logistics Supply Chain Management Mode Based on Information Network [J]. Research of Agricultural Modernization 2, 126-130.

Weill, P., Subramani, M., Broadbent, M., 2002. Building IT infrastructure for strategic agility. Sloan Management Review 44, 57-65.

White, A., Daniel, E.M., Mohdzain, M., 2005. The role of emergent information technologies and systems in enabling supply chain agility. International Journal of Information Management 25, 396-410.

Yang, L., 2015. FTZ offers opportunities for Fujian and Taiwan. CCTV.com. http://english.cntv.cn/2015/06/24/VIDE1435155962753281.shtml.

Zheng, Q., Han, Y., Li, S., Dong, J., Yan, L., Qin, J., 2009. E-commerce Case Analysis. Introduction to Ecommerce. Springer, pp. 458-517. 